\title{
Procrastination And Its Relationship With Business Students' Cheating Perceptions
}

\author{
Rafik Z. Elias, California State University, Los Angeles, USA
}

\begin{abstract}
The epidemic of college cheating is evolving to include more sophisticated schemes that are more difficult to detect. Business students' cheating is even more concerning because such behavior in college predicts workplace cheating (Nonis \& Swift, 2001). The current study examines procrastination as a personality variable that affects business students' perceptions of cheating ethics. A survey of 370 undergraduate and graduate business students was conducted. The results showed that low procrastinators were more likely to view cheating actions as more unethical compared to high procrastinators. Low procrastinators also had higher academic performance.
\end{abstract}

Keywords: College Cheating; Procrastination; Ethics

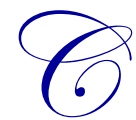

ollege cheating is a widespread phenomenon. A survey of alumni found that $86 \%$ of them cheated during college (Burton, Tapade \& Haynes, 2011). Business students were generally found to be more unethical compared to other majors and had more lenient attitudes toward cheating (Klein, Levenburg, McKendall \& Mothersell, 2007). Significant research had investigated demographic, situational, and psychological factors related to college cheating in an attempt to reduce its frequency.

The current study adds to the college cheating literature by introducing the psychological variable of procrastination as potentially related to college students' cheating. Procrastination in college was related to negative outcomes such as lower academic performance, higher levels of stress and dropping out of college (Hensley \& Cutshall, 2018). The current study links procrastination to the perception of cheating ethics. The results showed that business students who scored high on procrastination were more lenient towards cheating and perceived cheating actions as more ethical compared to low procrastinators.

\section{LITERATURE REVIEW}

\section{College Cheating and Business Students}

Cheating is defined as "a violation of intellectual property that goes against a university's academic integrity policy" (Molnar \& Kletke, 2012; 202). More cheating has been reported in all types of colleges in the last two decades. This includes low-tech cheating such as copying someone's homework or exam answers and high-tech cheating such as texting and plagiarism. The recent increase in online education has also resulted in increased cheating. King and Case (2014) found that $74 \%$ of students taking online classes felt cheating in an online exam was easy and $29 \%$ of them actually admitted to such cheating. Hollis (2018) attributed this widespread online cheating to students who fail to manage their time appropriately and quickly become overwhelmed by the class. Hollis (2018) even found a new method of online cheating that is gaining popularity: Ghost-student. This involves the student paying someone to take the online class on his/her behalf.

This widespread cheating culture has many negative consequences for higher education. First, the cheating student may get expelled from the university. Second, a publicized cheating culture within a particular university reduces the value of its degrees (McCabe, Butterfield \& Trevino, 2006) and results in grade inflation which eventually affects the employability of its graduates (Callahan, 2004). Finally, a cheating culture negatively affects non-cheaters because it forces the university to reduce flexibility and impose stricter standards on all students (Bloodgood, Turnley \& Mudrack, 2010). 
Significant research has investigated whether students in particular majors had different ethical perceptions regarding cheating. Earlier studies (e.g. McCabe \& Trevino, 1993) found that business students cheated more often compared to other students. Blau, Kunkle, Mittal, Rivera \& Ozkan (2017) confirmed these earlier findings and also found that business instructors who caught students cheating and reported them to the university perceived cheating as a much bigger problem than faculty who did not report such students. These results should be concerning to business educators and employers. Burton and Near (1995) considered cheating to be similar to dishonest behavior in an organization. They argued that overstating working hours is similar to cheating in an exam (Burton \& Near, 1995). Rawwas, AlKhatib \& Vitell (2004) also argued that students who plagiarize papers behave in a similar manner to employees who forge reports in order to be promoted. Simkin and McLeod (2010) attributed increased cheating among business students to "the desire to get ahead at all costs". Empirical results confirmed that college cheating strongly predicted workplace dishonest behavior (Nonis \& Swift, 2001). The current study specifically examines the ethical perceptions of various cheating actions among business students.

\section{Determinants of Cheating}

Significant research has examined the demographic, contextual and psychological factors related to cheating in college. Generally, male and younger students cheated more often compared to female and older students (Schuhmann, Burrus, Barber, Graham \& Elikai, 2013; Lonsdale, 2017). Lonsdale (2017) also found that students cheated more often on take-home assignments compared to in-class assignments and exams. Rawwas et al. (2004) found that business students perceived in-class cheating actions as more unethical than outside-class cheating actions.

Many studies have examined the psychological factors affecting cheating. Rettinger and Jordan (2005) found that religiosity had a positive effect on the likelihood of cheating. Bloodgood et al. (2010) showed that students scoring high on Machiavellianism were more tolerant of cheating in general compared to other students. Contrary to previous research, Yaniv, Siniver \& Tobol (2017) concluded that higher-achieving students were bigger cheaters. Hendy (2017) found that more conscientious students cheated less often compared to less conscientious students. Based on a thorough literature review, Stiles, Wong \& LaBeff (2018) concluded that highly-entitled students cheated more often in college compared to less-entitled students.

The current study uses the psychological variable of procrastination to examine the ethical perception of cheating.

\section{Procrastination and College Students}

Procrastination is a personality variable defined as "the inability to make a decision to act in a timely manner" (Chu \& Choi, 2005, 247). Lazarus and Folkman (1984) argued that procrastination is a function of a person's cognitive appraisal of a situation. When a person faces a challenging task, he/she assesses his/her ability to manage the task based on self-esteem and determines whether he/she is able to complete it. Research indicates that procrastination has many negative consequences on the quality of life. Lazarus and Folkman (1984) noted that procrastination increases stress and anxiety. Ferrari and Roster (2018) found that higher levels of procrastination contributed significantly to clutter problems.

In an academic setting, academic procrastination has been well-documented. It is defined as "the intentional delay of initiation or completion of important and timely academic activities" (Ziesat, Rosenthal \& White, 1978; 63). Academic procrastination is prevalent at the college level. Steel (2007) found that almost $50 \%$ of students are chronic procrastinators which eventually leads to significant problems. Students postpone studying for exams, writing papers, and keeping up with weekly homework. Academic research found that such procrastination resulted in the failure to meet deadlines (Steel, 2007), increased discomfort and stress (Sirois, 2014), and shame and guilt (Fee \& Tangney, 2000). Morris and Fritz (2015) found that procrastination was negatively related to academic performance. Ariani and Susilo (2018) found that procrastinators employed a surface-level study approach rather than a deep-level study approach. Research examined some determinants of procrastination and found a close connection between procrastination, impulsiveness, and lack of self-control (Steel, 2007). Corkin, Yu, Wolters \& Wiesner (2014) found that the classroom climate, such as course situational interest, and instructor support were strong determinants of academic procrastination among college students. 
Based on previous research documenting the negative consequences of academic procrastination, the current study examines its relationship to cheating perceptions. Mih and Mih (2016) argued that students with a fear of failure take on maladaptive behaviors such as disaffection and procrastination, which implicitly increases the risk for cheating on exams. Based on previous research, the current study examines the following hypothesis:

H1: Higher levels of academic procrastination are associated with lower levels of ethical perception of cheating actions.

The current study also examines demographic factors as potentially related to academic procrastination. Research in this area is limited. Balkis and Duru (2017) found that male students procrastinated more often than female students. Male students also suffered more negative consequences related to procrastination compared to female students such as lower grades and lower satisfaction with the college experience. The current study expands the previous literature by examining additional demographic factors.

H2: Gender, age, college major and grade are significantly related to the level of academic procrastination among business students.

\section{RESEARCH DESIGN}

\section{Sample Selection}

The current study surveyed undergraduate and graduate business students enrolled in different business courses at a large public AACSB-Accredited university. After obtaining necessary university approval, a survey was developed, and different instructors administered it during class time. Participation was voluntary, anonymous and had no effect on course grade. Students took about 15 minutes to complete this survey. Junior, Senior and Graduate business students were selected for this study because they were close to graduation, had a chance to fully adjust to college life and develop their college study habits. A useable sample of 370 students was obtained. Table 1 presents a description of the sample used in the study. As indicated in the table, the sample was almost equally split between male and female students. Most of the sample consisted of undergraduate and traditional-age students. The accounting major is the largest in the College of Business and therefore accounting majors are the largest group in the sample.

Table 1. Sample Demographic Characteristics $(\mathrm{N}=370)$

\begin{tabular}{|c|c|c|c|}
\hline Gender & $\#$ & Age & $\#$ \\
\hline Male & 181 & $<25$ years old & 247 \\
\hline Female & 189 & 25 years old or $>$ & 123 \\
\hline Class Grade & $\#$ & Major & $\#$ \\
\hline Junior & 102 & Accounting & 151 \\
\hline Senior & 198 & Management & 72 \\
\hline Graduate & 70 & Marketing & 50 \\
\hline CIS & 26 & & \\
\hline Finance & 33 & & \\
\hline General Business & 18 & & \\
\hline Non-Business & 20 & & \\
\hline
\end{tabular}

Overall GPA Mean (SD) was $3.10(.44)$

\section{Measurement}

The questionnaire developed by Simha, Armstrong \& Albert, (2012) was used to measure students' ethical perceptions of various cheating actions. It consists of 16 statements that measure students' ethical perceptions of potential cheating actions in-class (10 statements) and outside-class (6 statements). Each respondent was asked whether a particular action was ethical/unethical based on a seven-point scale $(1=$ highly ethical and $7=$ highly unethical $)$. Factor analysis was conducted and two factors for in-class and outside-class were obtained as well as a total score. Students were not specifically asked whether they would undertake each cheating action in order to avoid the social desirability bias 
where respondents answer ethical behavior questions in the expected way rather than recording their true ethical believes. This bias was first introduced by Edwards (1957) and has been extensively documented in ethical research. Therefore, ethical perception rather than ethical intention was examined in this study. Previous research using this survey showed that students perceived outside-class actions as more ethical than in-class actions (Elias, 2017).

Procrastination was measured using the instrument developed by Tuckman (1991). The 16-item questionnaire measured a person's agreement or disagreement with statements that indicate procrastination. A seven-point scale was used $(1=$ strongly disagree and $7=$ strongly agree $)$. Higher scores indicate higher procrastination tendencies. The questionnaire was used in several studies. Tuckman (1991) reported its validity and reliability as .86. Tuckman (2007) reported it at .89. Ozer, Sackes \& Tuckman, (2013) used it in a sample of Turkish college students and found that procrastination scores were negatively related to academic self-efficacy and self-esteem. Several attempts have confirmed that a one-factor solution for this instrument is the most reliable. Similar to Tuckman (2007), students were classified based on their scores as high-procrastinators (50-104) or low-procrastinators (24-49).

\section{STUDY RESULTS}

The first step in data analysis is to calculate variable means and standard deviations. The results are reported in Table 2 (Panel A). They indicate that business students in general had low procrastination tendencies (Mean of 3.28/7.00). However, the large standard deviation indicates a wide variability among students regarding procrastination tendencies. Regarding cheating ethical perception, the results confirm earlier studies that showed that students viewed outside-class actions as more ethical than in-class actions, although both types were viewed as unethical (Mean 6.04/7.00) with a small standard deviation. Elias (2017) examined demographic differences in ethical perceptions and found that female and nontraditional-age students viewed both types of cheating actions as more unethical compared to male and traditional-age students.

The second step involved a comparison of the means of high and low procrastinators' ethical perception of cheating actions. T-tests comparisons of the Means were used to conduct the analysis. The sample was divided into two groups: High procrastinators and low procrastinators based on the score of each student in comparison to the overall Mean of 3.28/7.00. There were a total of 193 students classified as high procrastinators (above the mean) and 177 students classified as low procrastinators (at or below the mean). The results (Panel B) indicated that low-procrastinators perceived cheating actions as more unethical compared to high-procrastinators. These results held true for in-class cheating, outside-class cheating and for overall cheating. The results also revealed that low-procrastinators had an overall higher GPA compared to high-procrastinators. H1 is therefore supported. 
Table 2. Procrastination and Cheating Ethics. $(\mathrm{N}=370)$

\begin{tabular}{|c|c|c|}
\hline \multicolumn{2}{|l|}{ Panel A: Variable Means } & Mean (SD) \\
\hline \multicolumn{2}{|l|}{ Procrastination score } & $\begin{array}{c}3.28^{*} \\
(1.16)\end{array}$ \\
\hline \multicolumn{2}{|l|}{ In-class cheating } & $\begin{array}{l}6.34^{* *} \\
(.91)\end{array}$ \\
\hline \multicolumn{2}{|l|}{ Outside-class Cheating } & $\begin{array}{l}5.85^{* *} \\
(.80)\end{array}$ \\
\hline \multicolumn{2}{|l|}{ Total cheating Perception } & $\begin{array}{l}6.04^{* *} \\
(.79)\end{array}$ \\
\hline \multicolumn{3}{|c|}{ Panel B: Relationship between Procrastination and Ethics } \\
\hline & High-Procrastinators $(n=193)$ & Low-Procrastinators $(n=177)$ \\
\hline In-class Cheating & $6.16+++$ & $6.54+++$ \\
\hline Outside-class Cheating & $5.65+++$ & $6.07+++$ \\
\hline Total Cheating & $5.84+++$ & $6.25+++$ \\
\hline GPA & $3.03+++$ & $3.17+++$ \\
\hline \multicolumn{3}{|c|}{ Panel C: Demographic Factors and Procrastination } \\
\hline \multicolumn{2}{|c|}{ Gender } & Mean (SD) \\
\hline \multicolumn{2}{|l|}{ Male } & $\begin{array}{l}3.44 \\
(1.17)++\end{array}$ \\
\hline \multicolumn{2}{|l|}{ Female } & $\begin{array}{l}3.13 \\
(1.14)++\end{array}$ \\
\hline \multicolumn{3}{|l|}{ Age } \\
\hline 25 years or $<$ & & $\begin{array}{l}3.39 \\
(1.13)++\end{array}$ \\
\hline$>25$ years & & $\begin{array}{l}3.03 \\
(1.21)++\end{array}$ \\
\hline
\end{tabular}

* Seven-point scale: Higher scores indicate higher procrastination tendencies

** Seven-point scale: Higher scores indicate higher perception that action is unethical.

$++\mathrm{p}<.05$;

$+++\mathrm{p}<.01$

Finally, demographic factors were examined in the context of procrastination. T-tests comparison of the mean procrastination scores were conducted using gender, age, class grade and major as comparison variables. There were no statistically significant differences in procrastination based on class grade or major. Only gender and age were statistically significant and therefore they are the only variables reported in Table 2 (Panel C). Male business students scored higher on procrastination compared to female students and younger students scored higher than older (nontraditional) students. $\mathrm{H} 2$ is therefore partially supported.

\section{DISCUSSION AND IMPLICATIONS}

The current study theorized that procrastination was related to cheating ethical perceptions among business students. Some results were comforting while others were alarming. Business students generally were low procrastinators. These are comforting results considering that the study revealed that low-procrastinators had higher academic achievement as measured by GPA. These results point to the importance of reducing procrastination among business students. Instructors can achieve this goal by showing all students, in particular high-procrastinators, the disadvantages of procrastination regarding their academic success. For example, instructors can achieve that goal by announcing tests well in advance. After the test, students can then be asked to fill out an anonymous survey asking them when they started studying for this test and their eventual grade. Overall results can then be shared with the whole class and the advantages of studying early for the test can be highlighted. Additional results involved low-procrastinators perceiving potential cheating actions as more unethical compared high-procrastinators. The current study can not establish causality but rather that a relationship simply exists. Instructors can emphasize the negative consequences of cheating and urge students not to procrastinate. Similar to the previous suggestion, the suggested survey can ask students who studied early for the test the likelihood of cheating on that particular test compared to those who started studying late and the overall results can be shared with the class. There were also some alarming findings. Male and 
younger students procrastinated more often than female and older students. These findings are similar to the ones reported by Balkis and Duru (2017) who argued that male students were more vulnerable to the destructive effects of academic procrastination compared to female students. The reasons for these differences can not be established in this study and should be the subject of further research in this area. However, this could be the subject of a class discussion where students can voluntarily be asked to share their procrastination experiences and state the reasons they procrastinated. These experiences can be beneficial to all students and especially male students. They can also give the instructor a good idea of the reasons leading to procrastination. When the author attempted such an experiment, several students indicated that the exam covered a large number of chapters and students did not have sufficient guidance on what to focus on. The author was able to make adjustments to the number of exams and chapters covered, which resulted in more favorable outcomes in future classes.

The current study's results are subject to the following limitation: The sample consisted of business students in only one public university located in a large metropolitan area. These results may or may not be replicated in other universities with different characteristics.

\section{AUTHOR BIOGRAPHY}

Rafik Z. Elias, is a Professor of Accounting at California State University, Los Angeles, USA. He received his Doctor of Business Administration in Accounting from Louisiana Tech University and he is a CPA. His research has been published in many top-tier journals and presented in national and international conferences. His research interests are in the areas of Business Education and Ethics.

\section{REFERENCES}

Ariani, D. W., \& Susilo, Y. S. (2018). Why do it later? Goal orientation, self-efficacy, test anxiety, on procrastination. Journal of Educational, Cultural and Psychological Studies, 17, 45-73.

Balkis, M., \& Duru, E. (2017). Gender differences in the relationship between academic procrastination, satisfaction with academic life and academic performance. Electronic Journal of Research in Educational Psychology, 15(1), 105-125.

Blau, G., Kunkle, M., Mittal, N., Rivera, M., \& Ozkan, B. (2017). Measuring business school faculty perceptions of student cheating. Journal of Education for Business, 92(6), 263-270.

Bloodgood, J. M., Turnley, W. H., \& Mudrack, P. E. (2010). Ethics instruction and the perceived acceptability of cheating. Journal of Business Ethics, 95, 23-37.

Burton, B. K., \& Near, J. (1995). Estimating the incidence of wrongdoing and whistle-blowing: Results of a study using randomized response technique. Journal of Business Ethics, 14, 17-30.

Burton, J. H., Tapade, S., \& Haynes, J. (2011). Religiosity and test-taking ethics among business school students. Journal of Academic \& Business Ethics, 4, 1-8.

Callahan, D. (2004). The Cheating Culture. Harcort: Orlando, FL.

Chu, A. H. C., \& Choi, J. N. (2005). Rethinking procrastination: Positive effect of active "procrastination" behavior on attitudes and performance. Journal of Social Psychology, 145(3), 245-264.

Corkin, D. M., Yu, S. L., Wolters, C. A., \& Wiesner, M. (2014). The role of the college classroom climate on academic procrastination. Learning and Individual Differences, 32, 294-303.

Edwards, A. (1957). The social desirability variable in personality assessment and research. The Dryden Press: New York, NY.

Elias, R. Z. (2017). Academic entitlement and its relationship with perception of cheating ethics. Journal of Education for Business, 92(4), 194-199.

Fee, R. L., \& Tangney, J. (2000). Procrastination: A means of avoiding shame or guilt? Journal of Social Behavior and Personality, 15(5), 167.

Ferrari, J. R., \& Roster, C. A. (2018). Delaying disposing: Examining the relationship between procrastination and clutter across generations. Current Psychology, 37, 426-431.

Hendy, N. T. (2017). Forced-choice personality measures and academic dishonesty: A comparative study. Journal of Academic Ethics, 15, 293-306.

Hensley, L. C., \& Cutshall, J. L. (2018). Procrastination in college: Students' readiness and resistance to change. Journal of College Student Development, 59(4), 498-504.

Hollis, L. P. (2018). Ghost-students and the new wave of online cheating for community college students. New Directions for Community Colleges, 183, 25-34.

King, D., \& Case, C. (2014). E-Cheating: Incidences and trends among college students. Issues in Information Systems, 15(1), 20-27.

Copyright by author(s); $\underline{\text { CC-BY }}$ 
Klein, H. A., Levenburg, N. M., McKendall, M., \& Mothersell, W. (2007). Cheating during the college years: How do business students compare? Journal of Business Ethics, 63, 197-206.

Lazarus, R. S., \& Folkman, S. (1984). Stress, Appraisal, and Coping. Springer: New York, NY.

Lonsdale, D. (2017). Intentions to cheat: Ajzen's planned behavior and goal-related personality facets. Journal of Psychology, 151(2), 113-129.

McCabe, D. L., \& Trevino, L. K. (1993). Academic dishonesty: Honor codes and other contextual influences. Journal of Higher Education, 64(5), 522-538.

McCabe, D. L., Butterfield, K. D., \& Trevino, L. K. (2006). Academic dishonesty in graduate business programs: Prevalence, causes, and proposed action. Academy of Management Learning and Education, 5(3), 294-305.

Mih, C., \& Mih, V. (2016). Fear of failure, disaffection and procrastination as mediators between controlled motivation and academic cheating. Cognition, Brain, Behavior: An Interdisciplinary Journal, 20(2), 117-132.

Molnar, K. K., \& Kletke, M. G. (2012). Does the type of cheating influence undergraduate students' perceptions of cheating? Journal of Academic Ethics, 10, 201-212.

Morris, P. E., \& Fritz, C. O. (2015). Conscientiousness and procrastination predict academic coursework marks rather than examination performance. Learning and Individual Differences, 39, 193-198.

Nonis, S. A., \& Swift, C. O. (2001). An examination of the relationship between academic dishonesty and workplace dishonesty: A multicampus investigation. Journal of Education for Business, 77(2), 69-77.

Ozer, B. U., Sackes, M., \& Tuckman, B. W. (2013). Psychometric properties of the Tuckman procrastination scale in a Turkish sample, Psychological Reports: Measures \& Statistics, 113(3), 874-884.

Rawwas, M., Al-Khatib, J., \& Vitell, S. (2004). Academic dishonesty: A cross-cultural comparison of U.S. and Chinese marketing students. Journal of Marketing Education, 26, 89-100.

Rettinger, D. A., \& Jordan, A. E. (2005). The relations among religion, motivation, and college cheating: A natural experiment. Ethics \& Behavior, 15(2), 107-129.

Schuhmann, P., Burrus, R., Barber, P., Graham, J., \& Elikai, M. (2013). Using the scenario method to analyze cheating behaviors. Journal of Academic Ethics, 11(1), 17-33.

Simha, A., Armstrong, J. P., \& Albert, J. F. (2012). Who leads and who lags? A comparison of cheating attitudes and behaviors among leadership and business students. Journal of Education for Business, 87(6), 316-324.

Simkin, M. G., \& McLeod, A. (2010). Why do college students cheat? Journal of Business Ethics, 94, 441-453.

Sirois, F. M. (2014). Procrastination and stress: Exploring the role of self-compassion. Self and Identity, 13(2), $128-145$.

Steel, P. (2007). The nature of procrastination: A meta-analytic and theoretical review of quintessential self-regulatory failure. Psychological Bulletin, 133, 65-94.

Stiles, B., Wong, N. C. W., \& LaBeff, E. E. (2018). College cheating thirty years later: The role of academic entitlement. Deviant Behavior, 39(7), 823-834.

Tuckman, B. W. (1991). The development and concurrent validity of the procrastination scale. Educational and Psychological Measurement, 51, 473-480.

Tuckman, B. W. (2007). The effect of motivational scaffolding on procrastinators' distance learning outcomes. Computers \& Education, 49, 414-422.

Yaniv, G., Siniver, E., \& Tobol, Y. (2017). Do higher achievers cheat less? An experiment of self-revealing individual cheating. Journal of Behavioral and Experimental Economics, 68, 91-96.

Ziesat, H. A., Rosenthal, T. L., \& White, G. M. (1978). Behavioral self-control in treating procrastination of studying. Psychological Reports, 42(1), 59-69. 
NOTES 